\title{
Growth temperature and reaction norms of morphometrical traits in a tropical drosophilid: Zaprionus indianus
}

\author{
DEV KARAN, BRIGITTE MORETEAU \& JEAN R. DAVID* \\ Laboratoire Populations, Génétique et Evolution, Centre National de la Recherche Scientifique, \\ 91198 Gif-sur-Yvette Cedex, France
}

\begin{abstract}
Ten isofemale lines of Zaprionus indianus were analysed to study the reaction norms of five morphometrical traits (wing and thorax length, body weight, sternopleural bristle and ovariole number) in relation to growth temperature. All these traits exhibited nonlinear concave reaction norms and were characterized by the coordinates of their maximum: MV (maximum value), and TMV (temperature of maximum value). Wing/thorax ratio, which is related to flight capacity, was also calculated and exhibited a monotonically decreasing reaction norm. Intraclass correlations were on average quite low, with no significant differences between traits, temperature or sex; a highly significant trait-temperature interaction was, however, observed. Sex dimorphism was very low in Zaprionus, contrasting with data previously obtained in other species. MVs among lines were positively correlated for the three size-related traits, whereas sternopleural bristle and ovariole number were genetically independent. TMVs were different between the traits, but higher than in D. melanogaster and other cold-adapted species, in agreement with the hypothesis that the norm shape evolves according to species thermal adaptation. MVs and TMVs were never correlated, indicating that mean values and plasticity are genetically independent. Some positive correlations were observed among TMVs of different traits, suggesting that the same genetic system might regulate plasticity of different traits.
\end{abstract}

Keywords: genetic correlations, isofemale lines heritability, phenotypic plasticity, reaction norms, Zaprionus indianus.

\section{Introduction}

Phenotypic plasticity, i.e. the capacity of a given genotype to produce different phenotypes in different environments, is of growing interest among evolutionary biologists (Via \& Lande, 1985; Scheiner \& Lyman, 1989; Scheiner, 1993; Via, 1993; Schlichting \& Pigliucci, 1998). As pointed out, for example by Roff (1997), two analytical approaches are available in quantitative genetic studies: on the one hand, different phenotypes in different environments may be considered as different traits linked by some genetic correlation; on the other hand, attention may be paid to the shape of the response curve in an environmental gradient, that is reaction norm.

In most ectotherm species, plasticity results in a smaller body size when ambient temperature increases (Atkinson \& Sibly, 1997; James et al., 1997). Latitudinal

*Correspondence. E-mail: david@pge.cnrs-gif.fr clines, which are known in several Drosophila species (see Karan et al., 1998a), also show smaller flies in warmer places. This parallelism between the effects of plasticity and genetic variation is an argument for an adaptive interpretation. However, as pointed out, for example by Partridge et al. (1994), we still do not know why it may be better to be smaller in a warmer climate even if several adaptive interpretations have been suggested (Atkinson \& Sibly, 1997).

In the case of D. melanogaster, the situation is still more complex because the reaction norms of body size according to growth temperature are not linear but exhibit a concave shape when the full thermal range is investigated (David et al., 1983, 1994). Such a nonlinear shape is also known for other fitness-related traits such as ovariole number (Delpuech et al., 1995), and in that case the maximum trait value is observed at a temperature close to the middle of the thermal range. For the description of such nonlinear reaction norms, it turned out that a convenient technique was to characterize a 
curve by the coordinates of the maximum. A comparison of different species living under various climates has shown that the shape of the reaction norms could be modified according to thermal adaptation; more precisely, cold-adapted species would show a maximum at a lower temperature and warm-adapted species a maximum at a higher temperature. So far, precise data are available for four different species: D. melanogaster (David et al., 1994), D. simulans (Morin et al., 1996), D. ananassae (Morin et al., 1997) and D. subobscura (Moreteau et al., 1997). Although these species exhibit different climatic adaptations, they all belong to the same taxonomic clade, i.e. the D. melanogaster group within the Sophophora subgenus of Drosophila.

In this paper, we choose to investigate a distantly related tropical species belonging to another genus, Zaprionus. Zaprionus species are big flies, typical of tropical African communities (Tsacas et al., 1981) but some of them have colonized other places. An example is $Z$. indianus, analysed here, which is widespread in India as well as in Africa. A natural population from southern India has been investigated, using the isofemale line technique, over its complete developmental thermal range, and we tried to answer several related questions: are the shapes of reaction norms of three sizerelated traits (wing and thorax length, and body weight) similar to those already seen in Sophophora? What is the reaction norm of another quantitative trait (sternopleural bristle number)? What is the genetic architecture of these traits and the possible interaction with growth temperature? Can we obtain some information on the genetic basis of reaction norms, and especially on their two characteristics: maximum trait value and temperature of maximum value? Can we correlate the characteristics of the norms with the tropical adaptation of the species?

We found concave reaction norms for all traits, with a maximum at a higher temperature than that of D. melanogaster. This agrees with the previous hypothesis that the position of the reaction norms along the temperature gradient changes according to thermal adaptation (Moreteau et al., 1997; Morin et al., 1999). Moreover, mean trait values and plasticity were not correlated, suggesting that they are under the control of different set of genes.

\section{Materials and methods}

A natural population of Zaprionus indianus was collected with banana-baited traps from south India (Bangalore: latitude: $12.6^{\circ} \mathrm{N}$ ) in March 1998 and used to establish isofemale lines at $20^{\circ} \mathrm{C}$. Subsequently 10 lines were randomly chosen, and, from each line, 10 pairs of flies of this first laboratory generation were used as parents. They were allowed to oviposit at room temperature $\left(20 \pm 1{ }^{\circ} \mathrm{C}\right)$ for about $10-12 \mathrm{~h}$ in culture vials containing a high-nutrient medium based on killed yeast (David \& Clavel, 1965). This type of food medium prevents crowding effects which could affect fly size, and the density ranged between 100 and 200 eggs per vial. These vials with eggs were immediately transferred to one of nine experimental temperatures $(12,13,14,17$, $\left.21,25,28,31,33^{\circ} \mathrm{C}\right)$. The flies measured thus correspond to the second laboratory generation, and this procedure is likely to eliminate possible maternal effects.

It turned out that development was never possible at $12^{\circ} \mathrm{C}$, and all individuals died in the pupal stage. At $13^{\circ} \mathrm{C}$, some adults were obtained in several lines but, in spite of repeated attempts, it was not possible to obtain a sufficient number in each line. At $14^{\circ} \mathrm{C}, 10$ males and 10 females were easily obtained for each line. At the upper end of the thermal range, a temperature of $33^{\circ} \mathrm{C}$ was always lethal. So the viable thermal range of $Z$. indianus may be defined as $14-32^{\circ} \mathrm{C}$.

For each line at each temperature above $13^{\circ} \mathrm{C}, 10$ males and 10 females were randomly taken and studied for different biometrical traits. The few adults obtained at $13^{\circ} \mathrm{C}$ were pooled in a single sample. Wing and thorax lengths were measured in both sexes with a binocular microscope equipped with a micrometer, and the results are expressed in $\mathrm{mm} \times 100$. Wing length was measured from the thoracic articulation to the distal tip of the wing and the thorax was measured on a left side view from the neck base to the tip of the scutellum, as in previous papers (David et al., 1994; Morin et al., 1996). Sternopleural bristles were also counted on both sides in the same fly. Ovariole number (both ovaries) was determined after dissection of females aged 5 to 8 days.

A preliminary experiment was performed to analyse body weight variation in males and females according to age. Groups of five males and five females grown at $21^{\circ} \mathrm{C}$ were established and food vials renewed daily. Each day, flies were slightly etherized, and the five individuals of each sex were weighed together on an electronic balance with a precision of $0.01 \mathrm{mg}$. It turned out that, as in D. melanogaster (Karan et al., 1998c), the weight was less variable in males than females so that the reaction norm of this trait was investigated in males only. Then, for each line and each temperature, males aged 4-5 days were weighed in a single group ( $n \approx 10-20)$ so that only a mean value was available, without an individual variance. Weight is expressed in $\mathrm{mg} \times 100$ per fly.

Data were analysed with Statistica software (Statistica, 1997). A major problem for reaction norm analysis is the choice of the polynomial level (see David et al., 1997). All traits measured here exhibited concave reaction norms with a maximum within the thermal 
range. We considered the mean curves, including the values at $13^{\circ} \mathrm{C}$ and calculated the coordinates of the maximum (MV: maximum value and TMV: temperature of the maximum value) both for quadratic and cubic adjustments. Adjusted $R^{2}$ were not very different according to the polynomial degree, and the MVs and TMVs were also similar. Polynomial adjustments were considered to be good for wing and thorax length and ovariole number $\left(R^{2}>0.95\right)$, less good for body weight $\left(R^{2}=0.80\right)$ and poor for sternopleural bristle number $\left(R^{2}<0.80\right)$. We also analysed, using the data of each line, the variations in slope according to temperature (see Morin et al., 1996; David et al., 1997). These empirical derivatives proved to be nonlinear for wing and thorax, leading us to prefer a 3 rd degree polynomial. Finally, for the sake of homogeneity, all traits were adjusted to a cubic polynomial, and characteristic values were calculated for each line.

\section{Results}

\section{Shape of reaction norms}

For wing length (Fig. 1a), females were slightly bigger than males, and the reaction norms were parallel, with a maximum around $18^{\circ} \mathrm{C}$. For thorax length, the maximum was observed at about $20^{\circ} \mathrm{C}$ and the sex difference was very small (Fig. 1b). These data were submitted to ANOVA (not shown): significant line, temperature and sex effects were observed for both traits, as well as a significant interaction between line and temperature. For ovariole number (Fig. 1c), a maximum was observed around $25^{\circ} \mathrm{C}$. As in D. melanogaster and other species (David et al., 1994; Morin et al., 1996, 1997; Moreteau et al., 1997), wing/thorax ratio exhibited a monotonic decreasing norm, with significantly higher values in females (Fig. 1d).
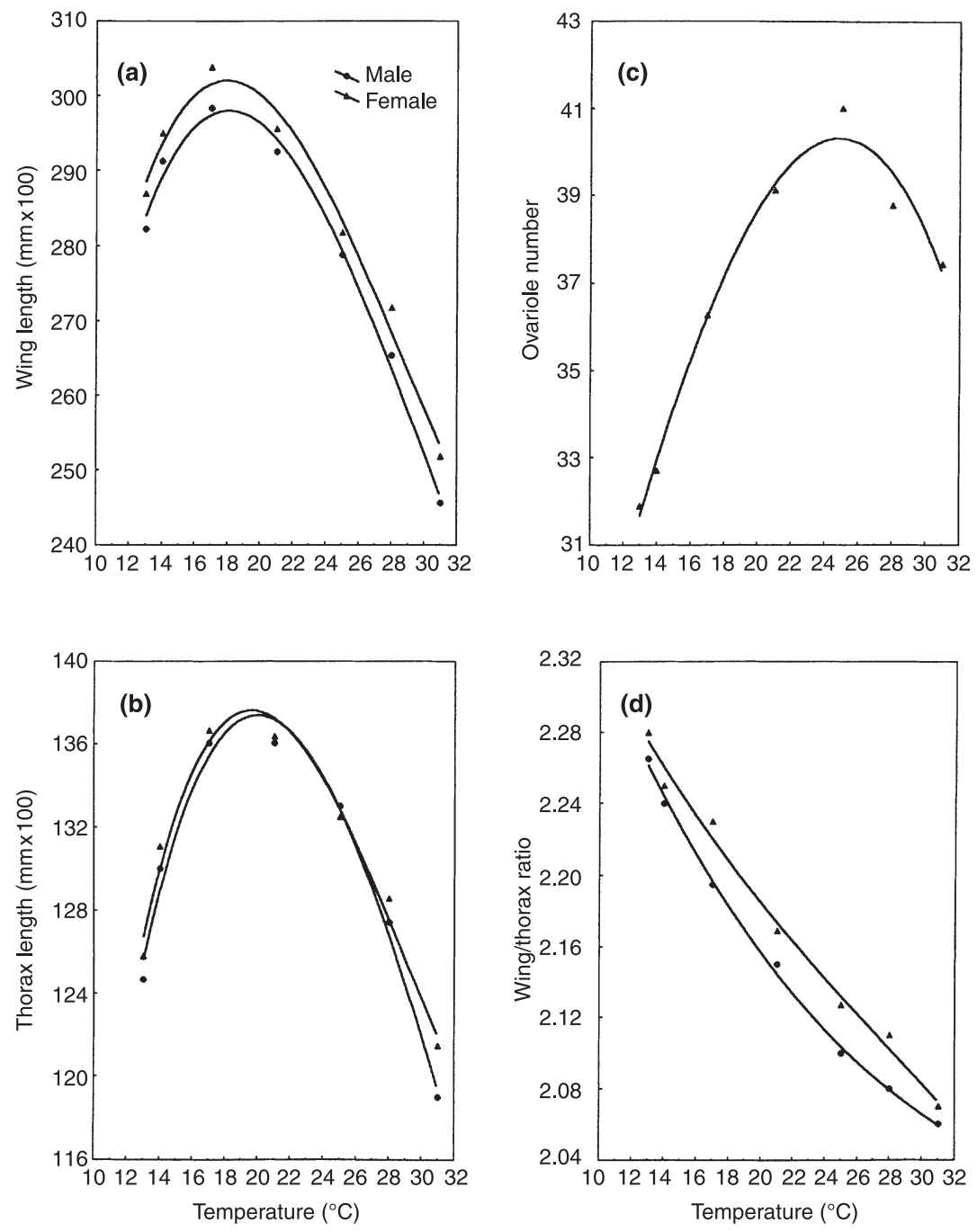

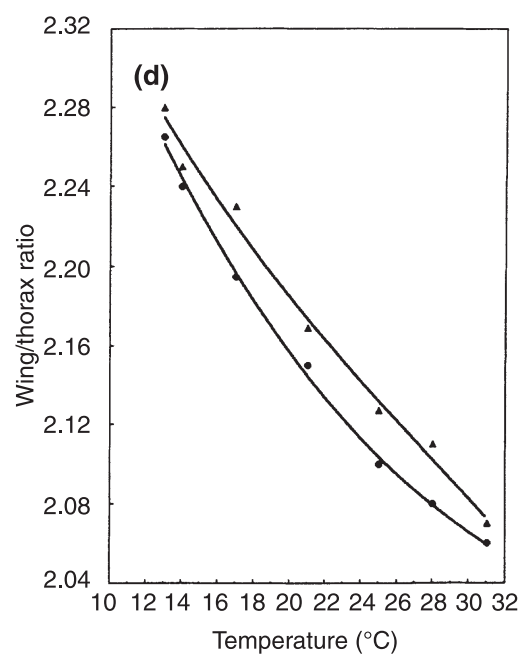

Fig. 1 Average reaction norms of (a) wing length (b) thorax length (c) ovariole number and (d) wing/thorax ratio in Zaprionus indianus, in relation to growth temperature, adjusted to a cubic polynomial.

(c) The Genetical Society of Great Britain, Heredity, 83, 398-407. 

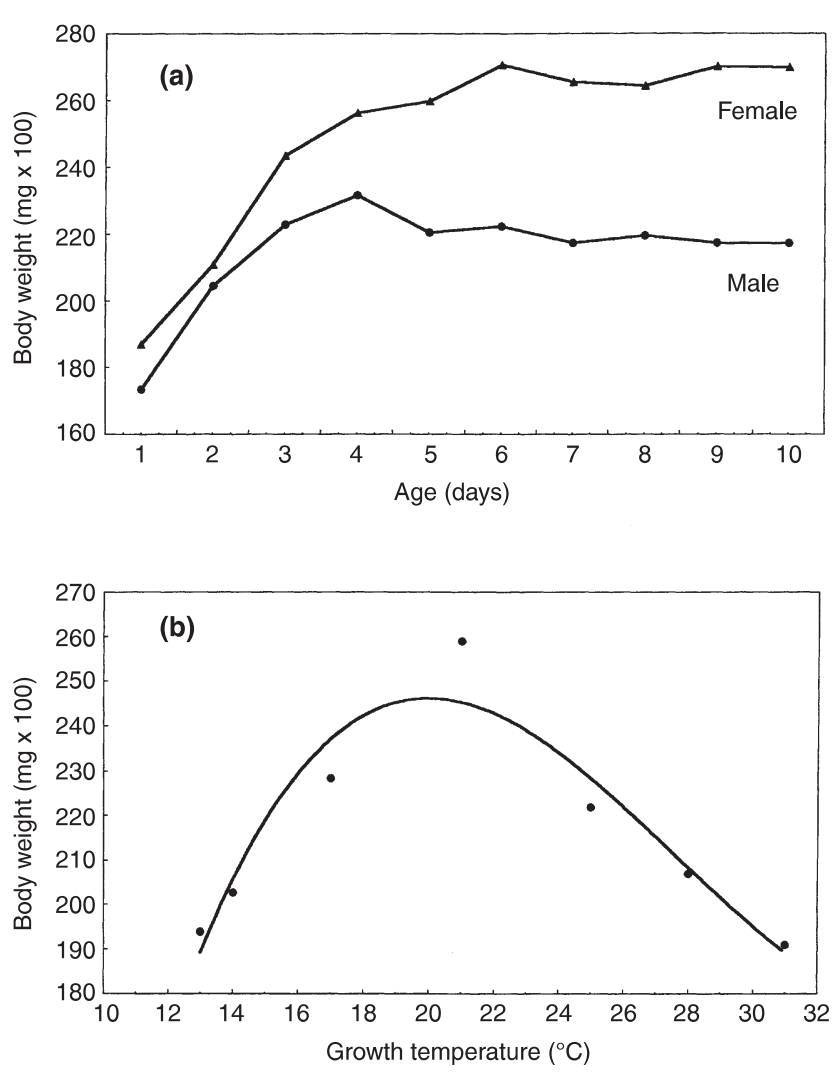

Fig. 2 (a) Variation of body weight of adult Zaprionus indianus (grown at $21^{\circ} \mathrm{C}$ ) according to age. (b) Average reaction norm of body weight (in males) in relation to growth temperature adjusted to a cubic polynomial.

Body weight variation was first investigated in flies grown at $21^{\circ} \mathrm{C}$, as a function of adult age (Fig. 2a). A sharp increase was found in males during the first 4 days, whereas in females this increase was observed for at least 6 days; oviposition started on 5th day. Reaction norms of body weight were measured in males only (Fig. 2b), and a maximum weight was shown around $20^{\circ} \mathrm{C}$.

For sternopleural bristles, polynomial adjustments did not provide a very convincing fit. However, the response curves, which are clearly different between females and males, also exhibited a maximum value at a temperature below $20^{\circ} \mathrm{C}$ (Fig. 3).

\section{Genetic variability among lines}

Curves shown in Figs 1,2,3 are the mean of 10 isofemale lines. Variation among the lines provides some information on the genetic variability in the original population, which is estimated by calculating the coefficient of intraclass correlation (Falconer, 1989). The intraclass correlation corresponds to a broad-sense heritability

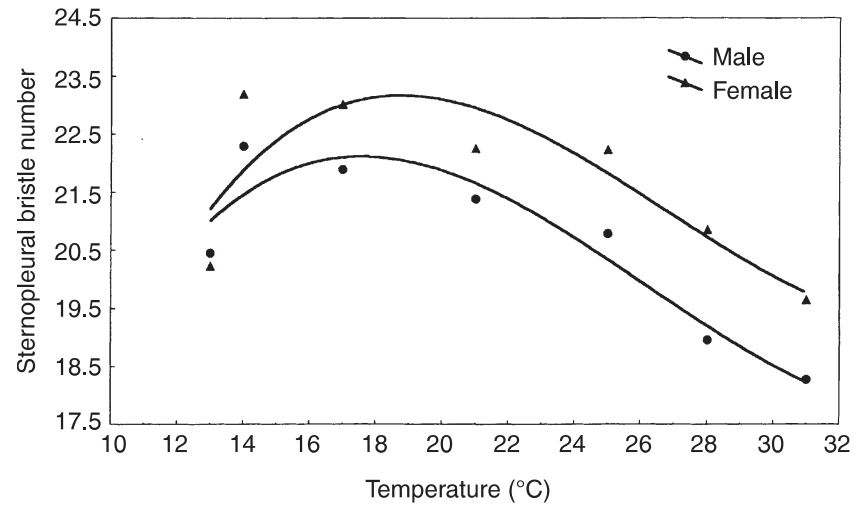

Fig. 3 Average reaction norm of sternopleural bristles in Zaprionus indianus in relation to growth temperature fitted to a cubic polynomial.

and is sometimes considered as a specific parameter, i.e. isofemale line heritability (Hoffmann \& Parsons, 1988; Capy et al., 1994; Gibert et al., 1998). Values of intraclass correlations according to sex, growth temperature and trait are given in Table 1. These data (except ovariole number) were submitted to ANOvA (not shown). No significant effect was found to be caused by temperature, sex or trait. The only significant effect was a temperature-trait interaction which explained $59.2 \%$ of total variability. The overall mean values for all traits were similar (average $=0.24 \pm 0.03$ ).

\section{Characteristic values of reaction norms}

As stated previously, the reaction norms of each line and each character were adjusted to a cubic polynomial and used to calculate the coordinates of a maximum (MV and TMV). In almost all cases, this adjustment was possible and provided a plausible value, i.e. a maximum within the thermal range of the species. The exception concerned sternopleural bristles, for which MVs and TMVs could be calculated for only eight and seven lines, for males and females, respectively (Table 2). Maximum wing length was longer in females whereas the sexes were almost identical for thorax lengths. Sternopleural bristles were more numerous in females, but not significantly so.

The temperatures of maximum value were not significantly different between the sexes but differed among traits: $17.7^{\circ} \mathrm{C}$ for wing length, $19.9^{\circ} \mathrm{C}$ for thorax length, $18.5^{\circ} \mathrm{C}$ for bristle number, $19.7^{\circ} \mathrm{C}$ for body weight and $25.1^{\circ} \mathrm{C}$ for ovariole number. Variation among lines, which corresponds to the genetic variability, was always less for MV than for TMV. Coefficients of variation (Table 2) were especially low for wing and thorax MVs (average $=1.13 \pm 0.14 \%$ ), and very high for sternopleural bristle TMVs (12\%). 
Table 1 Coefficients of intraclass correlation at various temperatures for wing and thorax length, wing/thorax ratio, sternopleural bristle and ovariole number in Zaprionus indianus

\begin{tabular}{|c|c|c|c|c|c|c|c|c|c|}
\hline \multirow{2}{*}{$\begin{array}{l}\text { Temperature } \\
{ }^{\circ} \mathrm{C}\end{array}$} & \multicolumn{2}{|c|}{ Wing length } & \multicolumn{2}{|c|}{ Thorax length } & \multicolumn{2}{|c|}{$\mathrm{W} / \mathrm{T}$ ratio } & \multicolumn{2}{|c|}{ St. bristles } & \multirow{2}{*}{$\begin{array}{c}\text { Ovariole no. } \\
\text { Females }\end{array}$} \\
\hline & $\mathrm{F}$ & M & $\mathrm{F}$ & M & $\mathrm{F}$ & $\mathrm{M}$ & $\mathrm{F}$ & M & \\
\hline 14 & 0.17 & 0.22 & 0.09 & 0.11 & 0.05 & 0.28 & 0.46 & 0.30 & 0.07 \\
\hline 17 & 0.17 & 0.16 & 0.12 & 0.21 & 0.73 & 0.25 & 0.20 & 0.23 & 0.18 \\
\hline 21 & 0.10 & 0.36 & 0.33 & 0.43 & 0.13 & 0.20 & 0.19 & 0.19 & 0.17 \\
\hline 25 & 0.24 & 0.27 & 0.20 & 0.22 & 0.17 & 0.12 & 0.20 & 0.15 & 0.15 \\
\hline 28 & 0.55 & 0.43 & 0.39 & 0.18 & 0.07 & 0.13 & 0.29 & 0.29 & 0.17 \\
\hline 31 & 0.26 & 0.23 & 0.27 & 0.21 & 0.39 & 0.21 & 0.21 & 0.23 & 0.38 \\
\hline Mean & 0.25 & 0.28 & 0.23 & 0.23 & 0.26 & 0.20 & 0.26 & 0.23 & 0.19 \\
\hline SE & 0.07 & 0.04 & 0.05 & 0.04 & 0.11 & 0.04 & 0.04 & 0.02 & 0.04 \\
\hline
\end{tabular}

F, female; M, male; St., sternopleural bristles; SE, standard error of the mean.

Table 2 Maximum value (MV) and temperature of maximum value (TMV) for wing and thorax length, sternopleural bristle number, ovariole number and body weight in Zaprionus indianus

\begin{tabular}{|c|c|c|c|c|c|}
\hline \multirow[b]{2}{*}{ Traits/sex } & \multirow[b]{2}{*}{$n$} & \multicolumn{2}{|l|}{ MV } & \multicolumn{2}{|l|}{ TMV } \\
\hline & & $m \pm \mathrm{SE}$ & $\mathrm{CV}$ & $m \pm \mathrm{SE}$ & $\mathrm{CV}$ \\
\hline \multicolumn{6}{|c|}{ Wing length } \\
\hline Female & 10 & $302.13 \pm 0.82$ & 0.86 & $17.50 \pm 0.21$ & 3.82 \\
\hline Male & 10 & $297.52 \pm 1.18$ & 1.25 & $17.98 \pm 0.37$ & 6.54 \\
\hline \multicolumn{6}{|c|}{ Thorax length } \\
\hline Female & 10 & $137.32 \pm 1.99$ & 1.45 & $19.62 \pm 0.85$ & 4.31 \\
\hline Male & 10 & $137.24 \pm 0.41$ & 0.95 & $20.19 \pm 0.39$ & 6.17 \\
\hline \multicolumn{6}{|c|}{ Sternopleural bristle number } \\
\hline Female & 7 & $22.84 \pm 0.37$ & 4.25 & $19.00 \pm 0.95$ & 13.29 \\
\hline Male & 8 & $22.03 \pm 0.45$ & 5.74 & $17.98 \pm 0.68$ & 10.63 \\
\hline \multicolumn{6}{|c|}{ Ovariole number } \\
\hline Female & 10 & $40.33 \pm 0.48$ & 3.76 & $25.13 \pm 0.52$ & 6.58 \\
\hline \multicolumn{6}{|c|}{ Body weight } \\
\hline Male & 10 & $241.96 \pm 4.08$ & 5.34 & $19.74 \pm 0.36$ & 5.74 \\
\hline
\end{tabular}

$n$, number of lines; $m$, mean of $n$ lines; SE, standard error of the mean; CV, coefficient of variation among lines.

\section{Correlations among characteristic values}

With respect to reaction norms, each line was characterized by two values. Maximum value (MV) is a quantitative trait measure whereas temperature of maximum value (TMV) characterizes the interaction between genotype and environment, and must be considered as a plasticity trait. Because each value was calculated by using the data of 60 flies, MV and TMV mainly express genetic characteristics of each line.
Correlations among MVs, TMVs, and between MVs and TMVs were analysed and 32 coefficients were calculated (Table 3). With such a high number of coefficients, some significant values are likely to occur by chance alone. We did not focus attention on single coefficients but tried to work out general trends by considering similar coefficients (e.g. between size-related traits), their sign and calculating a mean value. Maximum values between the three size-related traits were positively correlated (average value of four coefficients is 
Table 3 Correlation coefficients for characteristic values (MV: above diagonal; TMV: below diagonal), and between MV and TMV of reaction norms of morphometrical traits in Zaprionus indianus

\begin{tabular}{|c|c|c|c|c|c|c|}
\hline Traits & Sex & Wing & Thorax & St. bristles & Body weight & Ovariole \\
\hline \multirow[t]{2}{*}{ Wing } & $\mathrm{F}$ & & 0.74 & -0.19 & - & 0.13 \\
\hline & M & & 0.42 & -0.39 & 0.73 & - \\
\hline \multirow[t]{2}{*}{ Thorax } & $\mathrm{F}$ & 0.51 & & -0.49 & - & 0.20 \\
\hline & M & 0.60 & & -0.68 & 0.70 & - \\
\hline \multirow[t]{2}{*}{ St. bristles } & $\mathrm{F}$ & 0.71 & 0.26 & & - & - \\
\hline & M & -0.74 & -0.26 & & -0.15 & -0.74 \\
\hline \multirow[t]{2}{*}{ Body weight } & $\mathrm{F}$ & - & - & - & & \\
\hline & M & 0.33 & 0.67 & -0.23 & & \\
\hline \multirow[t]{2}{*}{ Ovariole } & $\mathrm{F}$ & 0.61 & 0.52 & 0.70 & & \\
\hline & M & - & - & - & & \\
\hline \multirow[t]{2}{*}{ MV and TMV } & $\mathrm{F}$ & 0.14 & -0.50 & -0.51 & & 0.42 \\
\hline & M & -0.66 & -0.15 & -0.29 & -0.21 & \\
\hline
\end{tabular}

These correlations are calculated from 10 isofemale line values for MV (maximum value) and TMV (temperature of maximum value), except for sternopleural (st.) bristles (eight lines for male and seven lines for female); significance threshold values for 10 observations are $0.67(P<0.05)$ and $0.70(P<0.001)$.

$0.65 \pm 0.08)$. All coefficients involving sternopleural bristles were negative (average $r=-0.44 \pm 0.10 ; n=6$ coefficients). Ovariole number was not correlated with size, but was negatively correlated with sternopleural bristles. For TMVs, a positive association was also found for the size-related traits $(r=0.53 \pm 0.07 ; n=4)$. Ovariole number was also correlated with other traits $(r=0.61 \pm 0.05 ; n=3)$. Sternopleural bristle number showed a contrasting pattern: there was no association with size $(r=-0.05 \pm 0.25 ; n=5)$ but a positive correlation with ovariole number $(r=0.70)$.

A most interesting observation concerned correlations between MVs and TMVs. The whole set of values showed an overall lack of correlation $(r=-0.22 \pm 0.13$; $n=8$ ). Trait values and plasticity should be considered as independent characteristics, as illustrated in Fig. 4.

\section{Correlations among sexes and sexual dimorphism}

At each growth temperature, mean line values were positively correlated between sexes, with average values of $r=0.67 \pm 0.10$ for wing, $r=0.64 \pm 0.01$ for thorax and $r=0.69 \pm 0.08$ for sternopleural bristles. For a given character in a given environment, the same set of genes is acting in the same direction in both sexes. Characteristic values of the reaction norms (Table 3) were also correlated between sexes (average $r=0.55 \pm$ $0.08 ; n=4)$ and this is illustrated in Fig. 5 for TMVs. We also considered the sexual dimorphism for each line at each temperature, by calculating the female/male ratio. For wing and thorax length, values were much lower in Z. indianus than in D. melanogaster (Fig. 6), and there was no significant increase according to growth temperature. Sexual dimorphism in $Z$. indianus was more pronounced for sternopleural bristles, with average values of $1.052 \pm 0.013$, than for wing $(1.017 \pm 0.002)$ and for thorax $(1.007 \pm 0.003)$. We also analysed wing/thorax ratio but no regular trend was observed according to temperature. The average value $(1.009 \pm 0.002)$ was similar to that in D. melanogaster $(1.003 \pm 0.003)$.

\section{Discussion}

In spite of their abundance in tropical communities, Zaprionus species have remained, until now, poorly investigated. In Indian populations of $Z$. indianus, latitudinal clines have been shown for body size (Karan, unpubl. obs.), and for desiccation and starvation tolerance (Karan et al., 1998b). With respect to size, the Bangalore population, investigated here, contains genetically small flies, in spite of the fact that their weight is more than twice that of $D$. melanogaster (Karan et al., 1998c).

For morphometrical, physiological and life history traits, D. melanogaster is certainly the best known drosophilid. A convenient way to discuss our data is to compare them to what is already known in D. melanogaster (David et al., 1994; Karan et al., 1998c). For temperature reaction norms in the 
Sophophora subgenus, results for three other species are available, namely $D$. simulans (Morin et al., 1996), D. ananassae (Morin et al., 1997) and D. subobscura (Moreteau et al., 1997).

The isofemale line procedure provided some information on the genetic variability of morphometrical traits. For wing and thorax length, sternopleural bristle and ovariole number, intraclass correlations were found to be less than the average values in D. melanogaster (Capy et al., 1994). We cannot tell, however, whether such differences reflect a regular property of the species or are caused only by a sampling effect of 10 lines only.

Sexual dimorphism of size is well marked in Sophophora but has been found to be very low in $Z$. indianus. Whether such a difference reflects a special sexual behaviour (e.g. male competition) remains to be investigated. Also in the four Sophophora species a sex difference has been observed in temperatures of maximum value:
TMVs are always less in males than in females. Such a difference apparently does not exist in $Z$. indianus. Adult reproductive strategies are very different with a long time of immaturity in females in $Z$. indianus ( 5 days against 1.5 in D. melanogaster). An unexpected result is the increase of body weight in Zaprionus males, whereas no such change is observed in D. melanogaster (Karan et al., 1998c). The physiological changes responsible for this weight variation remain to be investigated.

All five traits investigated (wing and thorax length, body weight, sternopleural bristle and ovariole number) exhibited concave reaction norms with a maximum falling within the developmental thermal range. This general shape may be now considered to be the rule in drosophilids, and investigators arguing about an adaptive relationship between size and temperature should also take into account the nonlinearity of the reaction norms (Atkinson \& Sibly, 1997). For a fitness-related
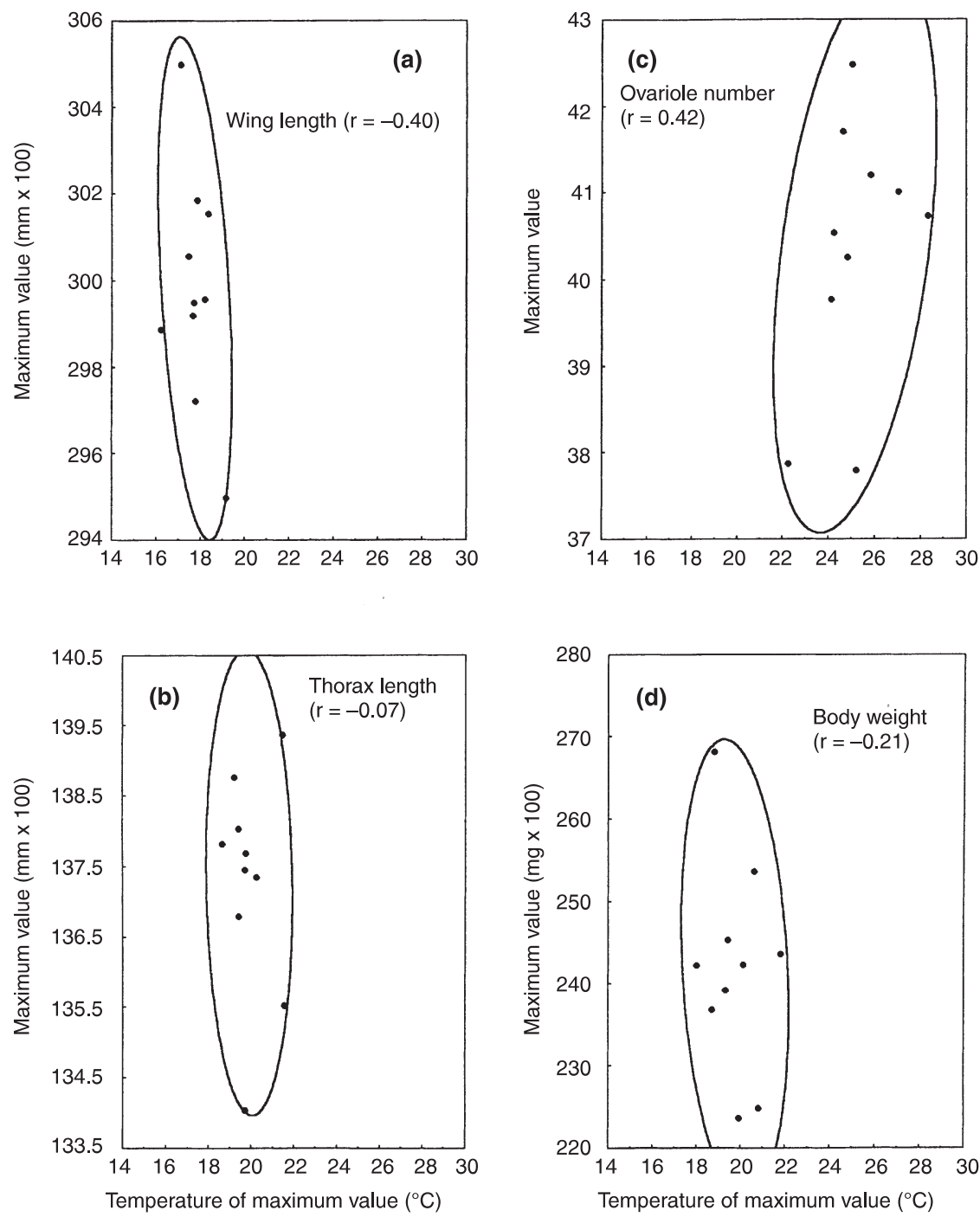

Fig. 4 Correlations between temperatures of maximum value (TMV) and maximum value (MV) for (a) wing (b) thorax (c) ovariole number and (d) body weight of Zaprionus indianus. Ellipses show a $90 \%$ confidence area.

(c) The Genetical Society of Great Britain, Heredity, 83, 398-407. 
trait like ovariole number, the decrease in $Z$. indianus begins below $25^{\circ} \mathrm{C}$, and the middle of the thermal range is $23^{\circ} \mathrm{C}$. The progressive decrease observed when lowering the temperature cannot be merely considered

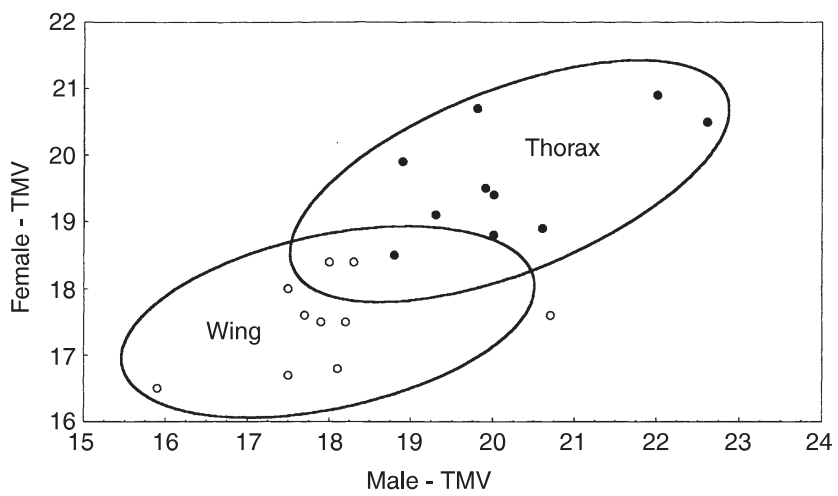

Fig. 5 Correlation between temperatures of maximum value (TMV) in Zaprionus indianus for males and females in wing and thorax lengths; ellipses show a $90 \%$ confidence area.

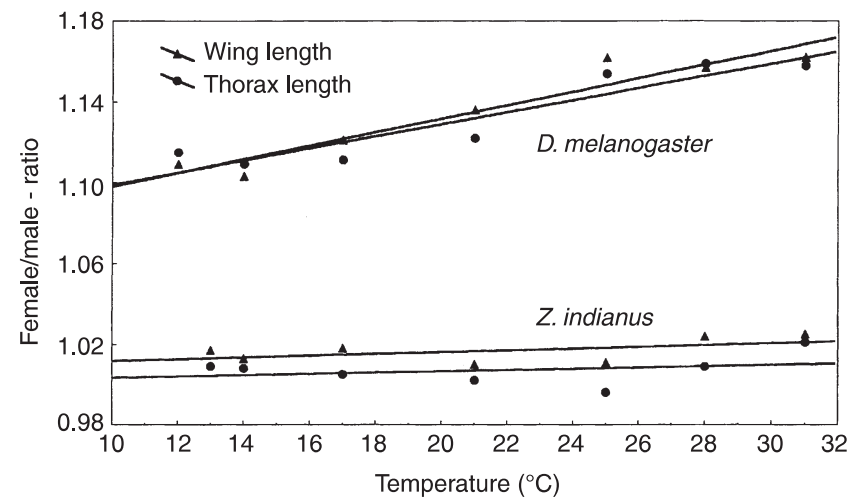

Fig. 6 A comparative account of sex dimorphism between Drosophila melanogaster and Zaprionus indianus with respect to growth temperature. as a contingent or maladaptive change. For the wing/ thorax ratio, which seems related to wing loading and flight capacity, we found a monotonically decreasing curve in $Z$. indianus, as in other drosophilids. The average value in $Z$. indianus is very low, as already found in the tropical D. ananassae (Morin et al., 1997). This observation agrees with the hypothesis that a warm environment favours a low wing/thorax ratio and a higher wing beat frequency (Pétavy et al., 1997).

The analysis of reaction norms has evidenced significant differences in mean trait values, which are expressed as significant variations in MVs. For the three size-related traits, MVs were significantly and positively correlated, in agreement with previous data on D. melanogaster (David et al., 1977, 1994; Karan, unpubl. obs.). On the other hand, ovariole number and sternopleural bristles in $Z$. indianus were, as in D. melanogaster (David et al., 1977), genetically independent of other traits.

A major conclusion of the present work has been that, on average, TMVs were not correlated to MVs. TMV, which indicates the position of a reaction norm along the temperature gradient, characterizes the reactivity of a trait to temperature and is, in other words, a plasticity character. The occurrence of specific plasticity genes for wing length has already been suggested by Scheiner \& Lyman (1989), but led to a scientific controversy (Scheiner, 1993; Via, 1993). We recently confirmed, in D. melanogaster, a genetic independence between MV and TMV for wing and thorax length (Karan, unpubl. obs.). Available $Z$. indianus data point in the same direction and suggest, moreover, that such a conclusion also applies to ovariole and sternopleural bristle numbers.

In D. melanogaster and other Sophophora flies, different traits exhibit different TMVs. This is obviously a major difficulty in identifying a maximum as representing a functional optimum (Moreteau et al., 1997). In the three species previously investigated, the order was TMV wing $<$ TMV thorax $<$ TMV ovarioles. The data presented

Table 4 Temperature of maximum value (TMV) for wing and thorax length (both sexes are averaged) and ovariole number according to the status of different drosophilids with their thermal range

\begin{tabular}{|c|c|c|c|c|c|c|}
\hline \multirow[b]{2}{*}{ Species } & \multirow[b]{2}{*}{ Status } & \multirow{2}{*}{$\begin{array}{l}\text { Investigated } \\
\text { population }\end{array}$} & \multirow{2}{*}{$\begin{array}{l}\text { Thermal range } \\
\left({ }^{\circ} \mathrm{C}\right)\end{array}$} & \multicolumn{3}{|c|}{ TMV } \\
\hline & & & & Wing length & Thorax length & Ovariole number \\
\hline D. melanogastertt & Cosmopolitan & France & $12-32$ & 15.2 & 18.3 & 22.2 \\
\hline D. simulans $\dagger$ & Cosmopolitan & France & $11-31$ & 12.3 & 15.2 & - \\
\hline D. subobscura§ & Temperate & France & $6-26$ & 11.1 & 12.8 & 13.3 \\
\hline D. ananassae & Tropical & India & $16-32$ & 17.9 & 22.7 & 24.6 \\
\hline Z. indianus & Tropical & India & $14-32$ & 17.7 & 19.9 & 25.1 \\
\hline
\end{tabular}

$\dagger$ Delpuech et al. (1995); \$Morin et al., 1996; §Moreteau et al., 1997; $₫$ Morin et al., 1997.

(C) The Genetical Society of Great Britain, Heredity, 83, 398-407. 
on $Z$. indianus confirm this order, which might reflect internal constraints during Drosophila development.

As argued previously (Moreteau et al., 1997; Morin et al., 1997) a major adaptive argument concerning the shape of reaction norms has been that TMVs were observed at lower temperatures in temperate species and higher temperatures in tropical ones. However, data were available for four species only, including two cosmopolitans having a tropical origin. Studies on $Z$. indianus extend our knowledge to five different species (Table 4), including two purely tropical. It is clear that the $Z$. indianus data are closer to those of $D$. ananassae, in agreement with the above hypothesis.

The correlations among TMVs of different traits have finally suggested an interesting new hypothesis. Positive correlations were observed between TMVs of the three size-related traits, between size and ovarioles, and also between ovarioles and sternopleural bristles. In other words, mean values of size-related traits and ovariole number are not correlated but their TMVs are correlated: the reaction norms of genetically independent traits might be under the control of the same set of plasticity genes. Obviously, such an hypothesis deserves further investigation.

\section{Acknowledgements}

This work was funded by the Indo-French Centre for the Promotion of Advanced Research (IFCPAR Project no. 1103-1). D.K. was supported as a postdoctoral fellow by IFCPAR. We also thank E. Pla for technical help in measuring ovariole numbers.

\section{References}

ATKINSON, D. AND SIBLY, R. M. 1997. Why are organisms usually bigger in colder environments? Making sense of a life history puzzle. Trends Ecol. Evol., 12, 235-239.

CAPY, P., PLA, E. AND DAVID, J. R. 1994. Phenotypic and genetic variability of morphometrical traits in natural populations of Drosophila melanogaster and D. simulans. II. Withinpopulation variability. Genet. Sel. Evol., 26, 15-28.

DAVID, J. R. AND CLAVEL, M. F. 1965. Interaction entre le génotype et le milieu d'élevage. Conséquences sur les caractéristiques du développement de la Drosophile. Bull. Biol. Fr. Belg., 99, 369-378.

DAVID, J. R., BOCQUET, C. AND DE SCHEEMAKER-LOUIS, M. 1977. Genetic latitudinal adaptation of Drosophila melanogaster: new discriminative biometrical traits between European and equatorial African populations. Genet. Res., 30, 247-255.

DAVID, J. R., ALLEMAND, R., VAN HERREWEGE, J. AND COHET, Y. 1983. Ecophysiology: abiotic factors. In: Ashburner, M. Carson, H. L. and Thompson, J. N., Jr (eds) The Genetics and Biology of Drosophila, vol. 3d, pp. 105-170. Academic Press, London.
DAVID, J. R., MORETEAU, B., GAUTHIER, J. P., PÉTAVY, G., STOCKEL, J. AND IMASHeVA, A. G. 1994. Reaction norms of size characters in relation to growth temperature in Drosophila melanogaster: an isofemale lines analysis. Genet. Sel. Evol., 26, 229-251.

DAVID, J. R., GIBERT, P., GRAVOT, E., PÉTAVy, G., MORIN, J. P., KARAN, ET AL. 1997. Phenotypic plasticity and developmental temperature in Drosophila: analysis and significance of reaction norms of morphometrical traits. J. Therm. Biol., 22, 441-451.

DELPUECH, J. M., MORETEAU, B., CHICHE, J., PLA, E., VOUIDIBIO, J. AND DAVID, J. R. 1995. Phenotypic plasticity and reaction norms in temperate and tropical populations of Drosophila melanogaster: ovarian size and developmental temperature. Evolution, 49, 670-675.

FALCONER, D. S. 1989. Introduction to Quantitative Genetics, 3rd edn. Longman, New York.

GIBERT, P., MORETEAU, B., MORETEAU, J. C. AND DAVID, J. R. 1998. Genetic variability of quantitative traits in Drosophila melanogaster (fruit fly) natural populations: analysis of wildliving flies and of several laboratory generations. Heredity, 80, 326-335.

HOFFMANN, A. A. AND PARSONS, P. A. 1988. The analysis of quantitative variation in natural populations with isofemale line strains. Genet. Sel. Evol., 20, 87-98.

JAMES, A. C., AZEVEDO, R. B. R. AND PARTRIDGE, L. 1997. Genetic and environmental responses to temperature of Drosophila melanogaster from a latitudinal cline. Genetics, 146, 881-890.

KARAN, D., MUNJAL, A. K., GIBERT, P., MORETEAU, B., PARKASH, R. AND DAVID, J. R. 1998a. Latitudinal clines for morphometrical traits in Drosophila kikkawai: a study of natural populations from the Indian subcontinent. Genet. Res., 70, 31-38.

KARAN, D., DAHIYA, N., MUNJAL, A. K., GIBERT, P., MORETEAU, B., PARKASH, R. ET AL. 1998b. Desiccation and starvation tolerance of adult Drosophila: opposite latitudinal clines in natural populations of three different species. Evolution, 52, $825-831$.

KARAN, D., MORIN, J. P., MORETEAU, B. AND DAVID, J. R. 1998c. Body size and developmental temperature in Drosophila melanogaster: analysis of body weight reaction norm. J. Therm. Biol., 23, 301-309.

MOReteAU, B., MORIN, J. P., GIBERT, P., PÉTAVy, G., PlA, E. AND DAVID, J. R. 1997. Evolutionary change of nonlinear reaction norms according to thermal adaptation: a comparison of two Drosophila species. C. R. Acad. Sci. Paris, 320, 833-841.

MORIN, J. P., MORETEAU, B., PÉTAVy, G., IMASHEVA, A. G. AND DAVID, J. R. 1996. Body size and developmental temperature in Drosophila simulans. Comparison of reaction norms with sympatric Drosophila melanogaster. Genet. Sel. Evol., 28, 415-436.

MORIN, J. P., MORETEAU, B., PÉTAVY, G., PARKASH, R. AND DAVID, J. R. 1997. Reaction norms of morphometrical traits in Drosophila: adaptive shape changes in a stenotherm circumtropical species. Evolution, 51, 1140-1148.

MORIN, J. P., MORETEAU, B., PÉTAVY, G., PARKASH, R. AND DAVID, J. R. 1999. Divergence of reaction norms of size characters 
between tropical and temperate populations of Drosophila melanogaster and D. simulans. J. Evol. Biol., 12, 329-339.

PARTRIDGE, L., BARRIE, B., FOWLER, K. AND FRENCH, V. 1994. Evolution and development of body size and cell size in Drosophila melanogaster in response to temperature. Evolution, 48, 1269-1276.

PÉTAVY, G., MORIN, J. P., MORETEAU, B. AND DAVID, J. R. 1997. Growth temperature and phenotypic plasticity in two Drosophila species: probable adaptive changes in flight capacities. J. Evol. Biol., 10, 875-887.

ROFF, D. A. 1997. Evolutionary Quantitative Genetics. Chapman \& Hall, London.

SCHEINER, S. M. 1993. Genetics and evolution of phenotypic plasticity. Ann. Rev. Ecol. Syst., 24, 35-68.

SCHEINER, S. M. AND LYMAN, R.F. 1989. The genetics of phenotypic plasticity. I. Heritability. J. Evol. Biol., 2, 95-107.
SChlichting, C. D. AND PIGLIUCCI, M. 1998. Phenotypic Evolution: A Reaction Norm Perspective. Sinauer Associates, Sunderland, MA.

STATISTICA. 1997. Statistics. Rel. 5.1. Statistica Statsoft Inc., Tulsa, OK.

TSACAS, L., LACHAISE, D. AND DAVID, J. R. 1981. Composition and biogeography of the Afrotropical drosophilid fauna. In: Ashburner, M., Carson, H. L. and Thompson, J. N., Jr (eds) The Genetics and Biology of Drosophila, vol. 3a, pp. 197-259. Academic Press, London.

VIA, s. 1993. Adaptive phenotypic plasticity: target or by-product of selection in a variable environment? Am. Nat., 142, 352-365.

VIA, S. AND LANDE, R. 1985. Genotype-environment interaction and the evolution of phenotypic plasticity. Evolution, 39, 505-522. 